\title{
Realidad y ficción literaria del maranchonero: muletero, tratante y rico
}

Muchas son las fábulas que se han contado y escrito acerca del origen de Maranchón, de sus gentes, la procedencia de su nombre, etc...

Lógicamente todo tiene su origen y en parte se debe a la propia idiosincrasia del pueblo maranchonero. Forma de ser que llamó la atención de algunos escritores del siglo pasado. Entre ellos cabe destacar a don Benito Pérez Galdós, quien vió a los maranchoneros de esta manera: "Son éstos los habitantes del no lejano pueblo de Maranchón, que desde tiempo inmemorial viene consagrado a la recría y tráfico de mulas".

Uno de los personajes de Narváez, de los Episodios Nacionales, llamado Miedes "veía en los maranchoneros una tribu cántabra, de carácter nómada, que se internó en el país de los Autrigones y Vardulios, y les enseñaba el comercio y la trashumación de ganados" ${ }^{1}$.

José Esteban en su breve e interesante ensayo Guadalajara en la obra de Galdós, añade más:

...recorren hoy ambas Castillas con su mular rebaño, y por su continua movilidad, por su hábito mercantil y su conocimiento de tan distintas regiones, son una familia, por no decir raza, muy despierta y tan ágil de pensamiento como de músculos. Alegran a los pueblos y los sacan de su somnolencia, soliviantan a las mujeres, dan vida a los negocios y propagan las fórmulas del crédito; es costumbre en ellos vender al fiado las mulas, sin más requisito que un pagaré cuya cobranza se hace después en estipuladas fechas; traen las noticias antes que los ordinarios, y son los que difunden por Castilla los dichos y modismos nuevos de origen matritense o andaluz. Su traje es airoso, con tendencia a los colorines, y con carreras de moneditas de plata por botones, en los chalecos; calzan borceguies; usan sombrero ancho o montera de piel; adornan sus mulitas con rojos borlones en las cabezadas y pretales, y les cuelgan cascabeles para que al entrar en los pueblos anuncien y repiqueteen bien la errante mercancía ?.

Tras esta larga cita, que a pesar de su extensión considero de gran interés para Maranchón, el mencionado autor -José Esteban- comenta

José Esteban, Guadalajara en la obra de Galdós (Madrid: Almarabu, 1985), p. 41. Cita el texto de Narváez perteneciente a los Episodios Nacionales. Véase Juan Carlos Estriban Lokrnte, -Molina en la Literatura (II). Galdós y su amigo molinés", Nueva Alcarria (11-X-1991).

2 J. Esteban, op. cit., pp. 41-42. 
sobre el párrafo anterior: "No cabe, a mi parecer, y yo llegué a conocer en su salsa a este pueblo de tratantes, ni más brillante ni más cabal definición de hombres y costumbres* ${ }^{3}$.

No sólo Galdós, también Pío Baroja dejó escritas algunas notas, aunque algo más breves, acerca de Maranchón y los maranchoneros, en que puede observarse su hombría de bien. En la quinta parte de su novela La nave de los locos, Rastros de la guerra, le dedica algunos párrafos.

Alvarito, el protagonista, sale de Sigüenza con dirección a Molina de Aragón en compañía del arriero "Malos Ajos" y del seminarista Tiburcio Lesmes. Poco después recogen a un gitano lañador por el camino. Comen y dos o tres horas antes de llegar a Maranchón comienza a llover por lo que han de guarecerse en una venta llamada significativamente del $\mathrm{Mal}$ Abrigon, donde intentan robarle, por lo que Alvarito decide emprender camino de nuevo:

Fue marchando de prisa por un páramo estéril y pedregoso, muy contento, hasta llegar a un pueblo: Maranchón.

Entró en una posada; junto a un hermoso fuego se calentó, y se fue a la cama.

Durmió de un tirón hasta muy entrada la mañana.

En Maranchón, pueblo de vendedores de caballos y de cerdos, se tiritaba de frío. Quedaban también allí recuerdos de Balmaseda. En 1836, el cabecilla, después de sorprender a la guarnición liberal del pueblo, se dedicó a una terrible matanza.

A la mañana siguiente, el arriero Malos Ajos y Tiburcio se presentaron a Alvarito en Maranchón y le preguntaron por qué causa se marchó, dejándolos.

...Alvarito se fue a ver al alcalde del pueblo, chalán que había estado en Bayona, quien le dijo que cortara toda relación con los dos tunantes y que unos días después podría seguir su viaje con un arriero de confianza '.

No tanta consideración - mas bien al contrario- tiene un artículo titulado "I.os muleteros maranchoneros" aparecido en La Ilustración Española y Americana, donde nuestros personajes son considerados poco menos que como salteadores de caminos. Transcribo seguidamente el citado artículo, que comenta las figuras que aparecen reproducidas en la revista:

Ocultos bajo los pliegues de esa brillante capa que se llama la civilización moderna, apenas aparecen en las grandes ciudades.

Su vida tiene mucho parecido con la de los gitanos, y aunque los muleteros maranchoneros son por lo general paisanos del inmortal Don Quijote, hay motivos para presumir, dadas sus costumbres, que cuando menos, son una rama desprendida del árbol de la gitanería.

Ibidem, p. 42.

- Seguimos la edición de Francisco Flores Arroyuelo de la obra mencionada (Madrid: Cátedra, S.A./Caro Raggio, 1987), pp. 257-259. También José Estriban, Guadalajara y Baroja (Sigüenza: Ed. Libería Rayuela, 1992), pp. 50-52. Además, J. C. Estrban Lorfntr, -Molina en la Literatura (I). Rescoldos carlistas en una novela de Baroja", Nueva Alcarria (27-1X-1991). 
El muletero que está apoyado en la vara de acebuche junto a la antigua reja de la casa de un pueblo, es un criado. Cerca de él están las yeguas con el cencerro, cuyo sonido reune en breve á las esparcidas muletas.

Ese jóven se ha criado en el campo, ha pasado todas las noches de su vida al raso, puede contar á los poetas que se levantan á las doce como sale la aurora, ni conoce el frío ni el calor, come siempre con buen apetito y es capaz de digerir piedras, duerme sobre la tierra sin mas almohada que su castoreño y nadie le gana á ocultar lacras en los animales, escamotear lo que encuentra al paso, ponderar las cualidades de las muletas, apurar un jarro de vino y dar una punalada al lucero del alba.

No le hableis de política, de arte, de nervios: no os entenderá. Preguntadle por el pelo de las mulas, por los corbejones, por el diente; habladle de las ferias, de unas magras de jamón y de un cane y le vereis animarse.

Estará en su elemento.

El personaje que aparece montado en una hermosa mula es el amo. Ya le ven ustedes qué gordo y qué templado. Lo menos lleva en el cinto que rodea su abdómen un centenar de oncejas.

En su casa guarda infinitas más en un arca de madera, ó las tiene enterradas en su huerta ó en su misma casa ha fabricado un agujero para esconderlas.

Es lo que se llama un hombre rico, y el ancho gabán con el que se preserva del frío es irrisorio. Pero con el calañés completa su pintoresca figura. Rara vez se rie y sus diez ó doce criados le temen mas que al coco los niños. Fl los trata de salvajes, de idiotas; pero les da el pan y esto basta para que le quieran y le teman.

Comparte con sus servidores las intemperies, con ellos recorre las ferias capitaneando seiscientas y mil mulas á veces, pasa la noche en su compañía cerca de los pueblos esperando á que amanezca para trasladarse al lugar de la feria, y sus órdenes son obedecidas ciegamente sin que á ninguno de sus criados se le ocurra apreciarlas.

Cualquiera al verle diria que era incapaz de hacer un buen negocio, pero esta vez engañan las apariencias. Tiene mucha gramática parda y no hay orador más elocuente que él, cuando se trata de vender una mula.

Después de recorrer las ferias vuelve á su casa, llevando una saya á su muger, y pañuelos de yerbas á sus hijas, oculta las onzas y vuelve a la faena.

Por regla general, el muletero propietario quiere que sus hijos sean abogados y cuando esto sucede, las monedas atesoradas por papá, se las llevan en Madrid. Capellanes, el tapete de los amigos íntimos.

Estos tipos desaparecerán muy pronto por completo, porque las onzas se van acabando, y ellos no entienden de otra moneda .

Si larga la cita, no menos interesante y sabrosa. Pero me da la impresión de que estas manifestaciones forman parte de un pasado que cada día se iba alejando más y más, si es que no llegó a desaparecer por completo, como señala el autor - por ahora desconocido- del artículo precedente. La imagen que ofrece parece demasiado desajustada, ridiculizante y caricaturesca. Algunas pinceladas son reales -lo fueron en el pasado- pero, en general, no se corresponden con la realidad.

Son formas de ver a los maranchoneros como grupo social fuertemente unido, y por tanto con capacidad de salir con desenvoltura de cualquier

"La Ilustración Española y Americana, núm. 2, 10-1-1870, pp. 28-29. 
situación. Al fin y al cabo parece que estas formas un tanto "folclóricas" de ver al maranchonero estaban quizás algo trasnochadas incluso en la época en que fueron escritas, un tanto "románticas" y otro tanto de "curioso impertinenten, de viajero que cuenta lo que ve, pero en este caso transformándolo según su libre albedrío y capricho, contribuyendo a montar la leyenda del maranchonero como grupo étnico más o menos "maldito", como sucedió con los vaqueiros de alzada, los maragatos, los agotes del valle de Baztán, los chuetas mallorquines, o simplemente los esquiladores de Fuentelsaz y Milmarcos, que también llegaron a emplear entre sí y en sus tratos una jerga especial, propia, llamada migaña ${ }^{6}$.

Lo que suele pasar es que siempre hay alquien que mantiene viva la llama del "romanticismo trasnochado" al que me he referido antes.

Aún hace poco tiempo se podía leer:

Los maranchoneros, en el antiguo pueblo de tratantes de mulas, blusón negro y tralla al hombro, pues el terreno de estas parameras, frío y duro en exceso, no permite más que una pobre agricultura cerealista y algo de ganadería. Por eso sus gentes se vieron obligadas en todo tiempo a vivir del trato y el comercio, emigrando muchos ${ }^{-}$.

Visión un tanto estereotipada y arrastrada de un molde anterior que no se diferencia mucho de esa otra forma de ver a los maranchoneros que tenía un sacerdote de la diócesis de Sigüenza, de 1886, que es la que sigue:

(Maranchón) tiene unos 420 vecinos en otras tantas casas de buena construcción, y nadie apenas ignora donde se halla situada esta villa; pues los marancbonéros, se encuentran en cualquier punto de España, comprando y vendiendo mulas, comerciando en pieles, jabón y cera. y siempre con su traje característico de calzón corto, sombrero, faja y medias azules y chaleco de pana ó terciopelo, con su indispensable botonadura de plata. No obstante su tráfico y vida vagabunda. todavía se conserva en Maranchón, aquella santa fe y catolicismo, que ha huido casi por completo de otros pueblos, con menos motivos ${ }^{8}$.

Vestimenta, como puede verse, que no varía gran cosa de aquella otra que vimos en la cita de Galdós. ¿Serían la faja y las medias azules las que dieran lugar a esa "tendencia a los colorines"?

Otro tema y forma de ver a los maranchoneros como adinerados a través de la muletería en determinados momentos, es decir, buscando la oportunidad, se da constantemente:

" M.a Rosa Nuno Girtrerraz, "El esquileo. Trabajo, Cultura y Comunicación en la Serranía de Guadalajaran. Cuadernos de Etnología de Guadalajara, 14-15 (1990). pp. 81-120. Asociación Cultural de Milmarcos, Vocabulario de La Migaña $(1979$, s.p.).

José SAnz y Diaz, alas fiestas de la Virgen de los Olmos", Programa Oficial de Fiestas (Maranchón, 1984 y 1985), 1 p.

* El obispado de Sigüenza ó sea nomenclator descriptivo, Geográfico y Estadístico de todos las pueblos del mismo, por un sacerdote de la diócesis (Zaragoza, 1886), p. 242. 
Bastantes de ellos hicieron dinero después de la guerra mundial de 1914 a 1918, vendiendo caballerías en el sur de Francia... ${ }^{9}$

Y también -donde vuelve a aparecer la guerra europea- esta otra cita, más cercana a la realidad:

En el primer cuarto de siglo actual aumentó considerablemente la población, levantándose buenas edificaciones, debido al enriquecimiento rápido de los tratantes - maranchoneros, que se dedican a la compra y venta de ganados por todas las regiones españolas, llegando incluso al sur de Francia. La guerra europea de 1914 a 1918 favoreció este comercio de los hábiles tratantes serranos ${ }^{10}$.

Volviendo a la vestimenta, tema que ha llamado mucho la atención, añade el mismo autor (Sanz y Díaz):

El tipo corriente de tratante maranchonero es alto, moreno, mirada resuelta y acostumbrada a otear los más diversos panoramas. Viste a la moderna traje de buen paño, se toca con boina, llevan en la mano como cetro de su oficio una espléndida tralla y se coloca encima del traje un amplio blusón de tela negra" ${ }^{14}$.

La variación que se advierte entre la indumentaria que se describe en esta cita y la que ofrecen los textos de Galdós, de La Ilustración Española y Americana, y del sacerdote de la diócesis seguntina, del siglo pasado, es notable. Si en aquellas se describe una vestimenta cuasi tradicional o "folclórica", ahora puede hablarse de cierta estandarización en el atuendo. En realidad, en nada se diferencia esta manera de vestir de la de otros chalanes y tratantes de ganados. Si nos apuramos, hasta poco se diferencia también de la de un vendedor de miel, de aquellos ambulantes, aunque a veces su blusón fuera gris y sustituyese la tralla, propia de arreadores, por las alforjas y el cubeto.

A través de la siguiente cita se insiste en el tema:

En general la población comenzó a dedicarse por entonces (se refiere el autor de la cita a los años finales del siglo xviI) a la trata de ganado, muy especialmente al mular, recorriendo lugares los más diversos de España con sus mercaderías y reuniendo grandes cantidades de dinero, que muchos aplicaron a construir grandes casonas en su pueblo ${ }^{12}$.

La fama del ganado mular que se criaba y recriaba en Maranchón fue grande. Los mulos eran apreciados por sus especiales características que los hacían muy aptos para labores de arriería - como se vio en Baroja-, para la realización de labores agrícolas y, en general, para arrastre de material pesado.

\footnotetext{
9. SANZ Y DIAZ, op. cit.

10. J. SANZ Y DiAz, El partido de Molina y sus advocaciones (Iconografía arqueológica) (Madrid, 1982), p. 44.

1 Idem, p. 45.

12 Antonio Herrera CASAdo, Crónica guia de la provincia de Guadalajara (Guadalajara: Diputación Provincial, 1983), p. 357.
} 


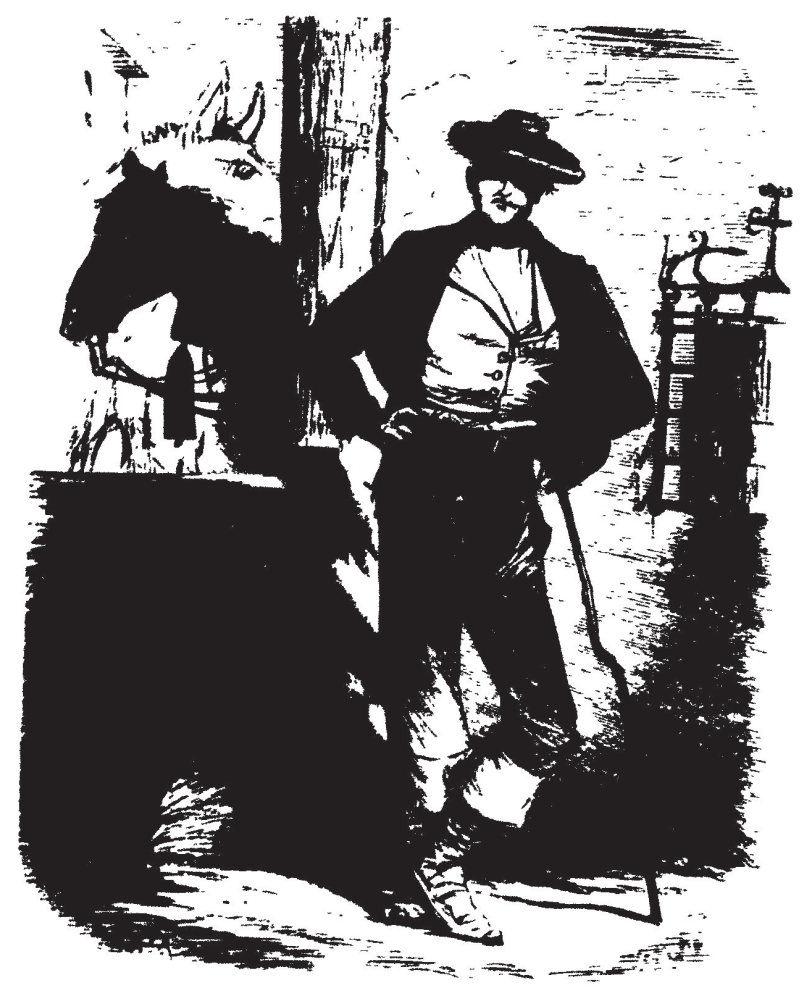

MULFTERO MARANCHONERO

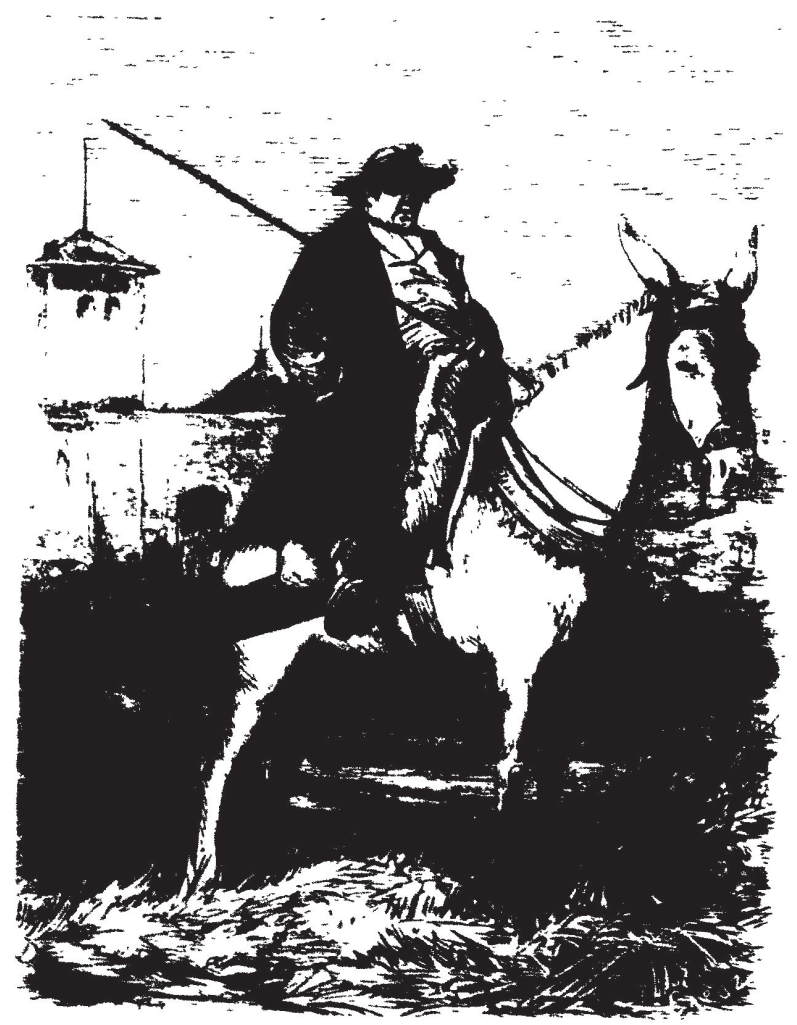

TRAFICANTE EN MULAS

(De La Ilustración Española y Americana) Año XIV-núm. 2, enero de 1870 , pp. 28 y 29. 
Don Antonio Pareja Serrada, que fue Cronista de Guadalajara, hace alusión a este ganado en una de sus conferencias. La cita corresponde a 1904, pero en ella se alude claramente a una fecha anterior:

En Maranchón se crían magníficos rebaños de mulos: la esbeltez de sus formas, sus férreos músculos, su buena sangre y la resistencia de que están dotados, los hacen insustituibles para el tiro y las faenas agricolas.

Hará unos diez años que uno de los regimientos de artilleria de guarnición de esta plaza [Madrid], necesitó mulas para sus baterías é hizo la convocatoria á la que acudieron muleteros de Maranchón. El Teniente Coronel, amigo mío, me invitó una tarde á ver el ganado y cuando desfilaba por el patio de maniobras del Cuartel de los Doks, me dijo, "Fijese V. en esos seis tiros que vienen los últimos". -iHermosos ejemplares! -contesté. "Son procedentes de la Alcarria, de un pueblo que llaman Maranchón y no hay animales de mejor sangre en toda el arma; resultan un poco bravos para la doma; pero una vez acostumbrados al ruido de los armones, son los más fuertes y el ganado más sóbrio que he conocido. Si hubiesen traido más, con todos me quedo".

Opinión tan respetable hace por sí sola el elogio del ganado de esta procedencia ".

No en vano fue Maranchón el lugar donde se estableció por parte del Empecinado el cuartel de adiestramiento de caballería durante la guerra de la Independencia ${ }^{14}$.

Hasta aquí esta breve muestra de citas literarias donde quedan bien patentes distintas formas de ver a los maranchoneros a lo largo de los tiempos.

JOSÉ RAMÓN LÓPEZ DE LOS MOZOS

Se contrastan descripciones y formas de ver la figura del maranchonero, más literarias que reales y según esquemas trasnochados, impregnados de cierto romanticismo que llega a considerarlos étnicamente emparentados con los gitanos. Destacamos las descripciones de su atuendo.

There are contrasting descriptions and viewpoints of the maranchonero personality, more from a literary aspect rather than from a real one, in accordance with out-of-date ideas impregnated with a certain romanticism which eventually compares them ethnically with the gipsies. The descriptions of their attire are particularly noteworthy.

12 Antonio Parfja Srrra1)a, La Alcarria. Conferencias pronunciadas en el Centro Alcarreño en los días 26 de marzo y 7 de mayo de 1904 (Guadalajara: Fstablecimiento Tipográfico La Región, 1904), p. 27.

1. José Ramón Lopez bF 104 Mozos, Maranchón en la Guerra de la Independencia (18101811) a través de algunos documentos (Madrid: Ayuntamiento de Maranchón, 1991). 